\title{
A multicentre survey of acute hospital nursing staff training in dementia care
}

\author{
Alice Coffey ${ }^{1}$, Mark Tyrrell ${ }^{1}$, Mary Buckley ${ }^{2}$, Edmund Manning ${ }^{2}$, Vanessa Browne ${ }^{2}$, Aoife Barrett ${ }^{2}$, \\ Suzanne Timmons ${ }^{2}$ \\ 1. School of Nursing and Midwifery, Brookfield Health Sciences Complex, University College Cork, Cork, I reland. 2. Centre
} for Gerontology and Rehabilitation, University College Cork, I reland.

Correspondence: Alice Coffey. Address: Catherine McAuley School of Nursing and Midwifery, University College Cork, Ireland. Email: a.coffey@ucc.ie

Received: May 27, 2014

DOI : $10.5430 /$ cns.v2n4p39
Accepted: July 25, 2014

Online Published: July 29, 2014

\section{Abstract}

Purpose: This paper reports on results of a study to identify education needs of nurses in acute care environments regarding dementia care in Ireland.

Method: As part of a multicentre study of dementia prevalence and in-hospital course, a survey was conducted with nurses $(\mathrm{n}=151)$ in six acute hospitals in the south of Ireland. Data were analysed using descriptive statistics.

Findings: Despite the availability of a national dementia education programme across all care services, $83 \%$ of acute hospital nursing staff perceived that they had insufficient training in dementia care, reflecting the known poor uptake of offered dementia education in acute hospitals. Over two thirds of nurses felt that education on dementia specific communication strategies was insufficient or unavailable. Nurses also reported insufficient knowledge with regard to pain assessment in patients with dementia, or alternatives to physical or chemical restraint. This lack of knowledge has implications for quality of care and may have consequences for safety of patients with dementia in acute hospitals in Ireland.

Conclusion: With the expected growth in prevalence of dementia worldwide, more people with dementia will access acute hospital care. Education and training to improve dementia care needs to be prioritised in acute hospitals at senior level.

\section{Key words}

Dementia education, Acute hospital, Nursing

\section{I ntroduction}

Dementia is a global issue of great concern to both developing and developed countries. There are about 35 million people around the world living with dementia, of whom approximately 7 million live in Western Europe” ${ }^{[1]}$.

The prevalence of dementia in Ireland is estimated at 41,470 and although estimates of future projections are calculated on several interrelated assumptions, dementia prevalence is likely to grow as our population ages ${ }^{[1]}$. Therefore more people with dementia are expected to be treated in acute hospital environments. In the UK, the Alzheimer's Society suggested that 
up to one quarter of hospital beds were occupied by people with dementia ${ }^{[2]}$. Irish data reveals that approximately $30 \%$ of older people admitted to an acute hospital have dementia ${ }^{[3]}$. In addition, the average length of stay in hospital of people diagnosed with dementia is significantly longer compared to other people over 65 years ${ }^{[4]}$ and mortality rates are higher ${ }^{[5]}$. The acute care environment is not always conducive to the requirements of persons with dementia, so hospital admission can lead to disorientation and confusion for a person with dementia, exacerbating the challenge of care. Studies conducted by the Alzheimer's Society in the UK, report a number of detrimental effects of hospital admission on patients with dementia, for example; extended duration of stay, institutionalisation and increased mortality ${ }^{[2]}$. Other poor outcomes of hospitalisation for people with dementia are falls, malnutrition and inappropriate pain management ${ }^{[6]}$.

\subsection{Staff knowledge and understanding of dementia care in acute settings}

Quality of life for people with dementia requires emphasis on more than just physical care ${ }^{[7]}$. Emotional, psychosocial and spiritual needs are also paramount ${ }^{[7]}$. Particular techniques are required to meaningfully communicate and interact with patients with dementia. When health professionals learn the appropriate techniques for communication and interaction, staff wellbeing is enhanced along with the patient's quality of life ${ }^{[8]}$. For a considerable time, studies have indicated a need for improved dementia education and training for nurses and other health care staff in acute services. Smith suggested in 2001 that staff misinterpretation of communication and misunderstanding of dementia could trigger responsive behaviours ${ }^{[9]}$. Over ten years later, Moyle still reported a lack of understanding among staff of the differences between acute and chronic confusion ${ }^{[10]}$. In their study, focused on the management of patients with dementia in the acute care environment in Australia, Moyle et al. reported widespread use of chemical and physical restraint ${ }^{[10]}$. Other studies found that nutritional needs of patients with dementia were not assessed or adequate nutritional support provided ${ }^{[2,11,12]}$. In an Irish study, families of patients with dementia also reported unpleasant experiences of hospitalisation ${ }^{[13]}$. These experiences included ignoring, disempowerment, infantilisation and stigmatization of the individual that according to the researchers "gradually undermined the individual" ${ }^{[13]}$. Awareness and understanding of dementia by frontline health care staff should therefore be priority. Nonetheless a recent UK National Audit of Dementia Care found that only 5\% of all hospitals had mandatory training in awareness of dementia for staff and less than one-quarter had a strategy identifying the necessary skill development ${ }^{[14]}$.

\subsection{Nurse education for dementia care}

Knowledge and skills in dementia care have been cited as essential to delivery of high quality care for people with dementia in the acute environment ${ }^{[15]}$. Research by Kada et al, provided evidence that dementia training for staff increased positive attitudes towards patients with dementia, in addition to improvements in staff competency levels ${ }^{[16]}$. However in the opinion of Moyle et al, organisational change is also necessary for training to affect acute care outcomes for patients with dementia in the long term ${ }^{[10]}$. Charter and Hughes conducted a qualitative study using focus groups with Healthcare Assistants and Staff Nurses in the UK to generate ideas that would improve dementia education for healthcare workers in hospitals ${ }^{[15]}$. Their findings suggest that practice-based teaching for healthcare staff should be developed and they recommend multifaceted educational strategies to address the complex learning needs of staff ${ }^{[15]}$. This multifaceted approach had previously been advocated by Grant, Kane, Potthoff \& Ryden in their study of staff training for Alzheimer's Care in the US ${ }^{[17]}$. Suggestions were that staff development in dementia care should include both formal and active learning experiences.

Challenges of caring for older patients with dementia in a structurally inadequate and inappropriate environment were highlighted in 2007 in a study by Nolan exploring nurses' experiences of caring for older people with dementia ${ }^{[18]}$. In this qualitative study, nurses acknowledged that the specific needs of patients with dementia were mainly not considered within an acute hospital environment ${ }^{[18]}$. Student nurses experiences of caring for people with dementia according to Baillie influence their future roles in caring for these patients' needs. Therefore, supportive learning environments that 
encourage students to spend time with patients, build relationships with informal carers, and get to know the person with dementia, are invaluable to the development of future nurses' knowledge, skills and attitudes ${ }^{[19,20]}$.

Education and training for dementia care has been examined for its relevance and adequacy by a number of researchers. In their review of dementia nursing competencies, consisting of 59 publications relevant to dementia nursing, Traynor, Inoue \& Crookes concluded that there was no competency framework relevant across different levels of practice ${ }^{\text {[21] }}$. According to these researchers, relevance across levels of nursing practice needed to be a priority for competency development ${ }^{\text {[21] }}$. In addition, research examining staff perception of the adequacy of their training in dementia care highlighted deficits. In the UK, Gandasha et al. conducted a large study, representing almost all NHS trusts, on health care professionals' (nurses, doctors and health care assistants) perception of the adequacy of their training in dementia care ${ }^{[22]}$. The findings from this survey of 2210 hospital staff in England and Wales were that staff mainly perceived their training to be inadequate ${ }^{[22]}$. Areas of specific concern to nurses were training in assessment of cognitive ability and management of challenging behaviour. Less than one third of nurses in the sample rated their education as adequate in the areas of assessment to recognise the stage of dementia and management of associated behaviours ${ }^{[22]}$. An Irish study found that responsive behaviour in acute hospital settings is most often associated with progressive dementia ${ }^{[23]}$. Yet the level of training and education for dementia care in Irish acute hospitals is poor. According to De Siún and Manning, 95\% of nurses in general hospitals had not received training in dementia care in $2010^{[24]}$. The importance of addressing the gaps in staff knowledge and skills has been highlighted in National Dementia Strategies in the UK, including all staff in general hospitals. For example, the Northern Ireland Dementia Services Development Centre (DSDC) developed a resource pack for Health and Social Care Trusts to enhance knowledge on dementia in acute care settings ${ }^{[25]}$. In Ireland, greater dementia awareness through enhanced training and education for all staff was highlighted as one of the keys areas for improvement in the care experience of people with dementia in general hospital settings ${ }^{[1]}$.

A Dementia Education Programme was made available to services in the Health Service Executive (HSE) nationally in Ireland in 2010. A suite of education programmes for nursing staff and care attendants based on a preceding needs analysis was developed. The education included a core generic awareness education programme, a National Qualifications Framework level 8 Dementia Champion module, a specialist module in responsive behaviour, an e-learning course on the early identification of memory problems, posters on delirium identification and a Carers Handbook \& CD. It was evaluated in 2012, using postal questionnaires and telephone interviews to selected programme co-ordinators \& participants, and all responded very favourably ${ }^{[26]}$. However, despite the programme being available to all services, the uptake from the acute sector has been very poor to date.

To determine the knowledge and training needs of nurses in acute hospital settings regarding dementia care, a study was conducted in acute hospital settings in the HSE South region in Ireland in 2012.

\section{Method}

This study was nested within an ongoing multicentre study of dementia prevalence, in-hospital course and long-term outcomes (the Cork Dementia Study, http://www.ucc.ie/en/charge-ucc/odcacs/). The six study hospitals in the south of Ireland included five publicly-funded acute hospitals, and one private hospital, with in-patient bed numbers ranging from 72 to 611 . Three of these hospitals were university affiliated. Within the six hospitals, a convenience sample of 260 ward-based nursing staff, of all grades, was selected, with a pre-defined sample number per hospital, based on hospital size (20-90 nurses per hospital). Wards were chosen at random within the larger hospitals, but had to include at least one medical and surgical ward, and in addition the intensive care unit, coronary care unit, geriatric ward and orthopaedic ward (if available within the hospital). Within the two small hospitals, all wards were included. The targeted nurses were working "day duty" during the two recruitment days at each site, and represented approximately one-third of the total nursing complement on the included wards. All participants were personally approached to participate by the data collectors and were offered the choice to complete the survey online (Survey Monkey ${ }^{\mathcal{O}}$ ) or to complete an identical paper 
survey which was collected on the ward at a later stage (addressed envelopes provided) and entered electronically into the survey by the data collectors. All participants were contacted in person or by telephone/email within two weeks and again at one month, and the survey was closed two weeks after final reminders.

The aim of the survey was to gather data on dementia awareness among staff, support available in caring for a person with dementia, and training, learning and development opportunities that were provided to staff. The survey questionnaire was a modified version of the instrument used for the National Audit of Dementia UK ${ }^{[11]}$. No staff-identifiable data was requested. Ethical approval was obtained from the Clinical Research Ethics Committee for the region. Data were extracted from the survey tool into a Microsoft Excel database and subsequently analysed using descriptive statistics.

\section{Results}

\subsection{Profile of respondents}

Data were collected from 151 nurses across the six hospitals. The response rate varied between hospitals, from $33 \%$ in the private hospital to $80 \%$ in two other hospitals, with an overall response rate of 58\%. With regards to respondents' clinical specialty, 44 worked in surgical units, 42 medical units, 26 mixed medical/ surgical, 9 in care of older adult (geriatrics), 11 emergency departments (ED) and 19 Intensive or coronary care nurses (ICU/CCU).

Seventy two percent of the nurse respondents were employed as staff nurses, $15 \%$ were clinical nurse managers grade 1 (CNM1), and 13\% were clinical nurse managers grade 2 (CNM2).

\subsection{Nurses' perception of the sufficiency of their education in dementia care}

Nurses were asked to rate the adequacy of their overall education in dementia and their education on specific aspects of dementia care as sufficient, insufficient or unavailable. Although almost three quarters of respondents rated their education on person centred principles of care as sufficient, only $16 \%$ perceived that they had sufficient training in dementia specific care compared to $32 \%$ in the UK survey). Just over half of the sample (58\%) rated their education regarding palliative care for people with dementia as sufficient. Despite this, less than one in three rated education on pain assessment in persons with dementia as being sufficient. Other aspects of dementia specific education were also rated unfavourably. For example; education on assessment of cognitive ability was rated as insufficient by $64 \%$, and over $70 \%$ felt that their education on dementia specific communication strategies was insufficient or unavailable. Less than half of the sample (42\%) felt that education on the management of patient behaviours was sufficient and only $17 \%$ rated dementia awareness training as being sufficient. Education on avoiding physical or chemical restraints was either insufficient or unavailable according to half of the respondents (51\%), with a similar number rating education pertaining to adult protection policy and procedures as being either insufficient or unavailable. Finally, only two individuals indicated that they had been refused access to education or training specifically related to care of people with dementia. In both cases, these respondents indicated that this refusal was due to lack of staff cover on their unit at the time the education/training was available.

\subsection{Nurses' preparedness for caring for people with dementia}

Nurses' knowledge and understanding of dementia and their preparedness for caring for persons with dementia is essential to high quality care. Respondents were asked to rate their knowledge about dementia and their perceived degree of preparedness for caring for people with dementia. Responses were provided on a 5 point Likert scale. Almost $90 \%$ either agreed or strongly agreed that they were aware of how dementia can affect a person's behaviour and their ability to communicate; with just over two thirds indicating that they felt they had adequate knowledge and understanding of the needs of people with dementia and how to assist them. Less than half of the respondents, however, agreed or strongly agreed that they were aware of the different types of dementia; what it is like living with dementia, and in what ways people 
with dementia need support (42\%), with a similar number agreeing that they had sufficient knowledge to assess patients' capacity, and to involve them in decision making regarding their care and treatment.

When asked about their awareness of the difficulties they may be faced with when interacting with patients who had dementia, just over half of the respondents agreed or strongly agreed that they were aware of these difficulties or had been given guidance on how to manage the challenges that may arise. Only two thirds of respondents agreed or strongly agreed that they were aware of current legislation surrounding capacity and actions taken to deprive a person of their liberty.

With regard to their perceived degree of preparedness for interaction with carers, less than half of respondents indicated that they had sufficient knowledge and understanding of dementia to discuss difficulties that may be ahead of carers, to discuss care and management options, or to inform them of support that is available to them. Nevertheless, $70 \%$ indicated that they were encouraged and supported by colleagues and management to develop their knowledge and understanding of dementia, and almost all of the respondents (97\%) were of the view that further staff training would be beneficial, and would improve the level of care people with dementia receive.

\subsection{Nurses perception of the adequacy of resources to support them in care provision}

The adequacy of resources available to nurses in order to support care in practice was examined using questions on staffing levels, the work environment and supports available. Responses were recorded as yes / no / don't know. With regard to respondents perceptions of the adequacy of resources available to them for providing quality care, only $16 \%$ agreed that staffing on their wards were sufficient to provide one to one nursing care when required, and just over one in three (35\%) felt that there were enough staff on the ward at all times to ensure patients are assisted if required with personal care, personal hygiene, mobilising, and at mealtimes. Although, $67 \%$ of respondents indicated that a system was in place whereby they could report incidents of inadequate staffing levels if they deemed this to be a risk to patients in their care, just one in three felt that such reports were dealt with in a timely manner.

Less than half (49\%) of respondents reported that they had enough time to regularly discuss matters with the patient and/or their carer regarding progress of care and approaches to treatment. Equally less than half felt that they had enough time to ensure that patients are comfortable in their environment, or to support any patients who were unfamiliar with and/or disorientated by their environment. The majority of respondents however indicated that patients on their unit and their carers were able to convey information in a confidential manner. While $69 \%$ of respondents indicated that there was a system in place on their unit to ensure that all staff with patient contact were made aware that some patients on the unit had dementia, one in 10 were not aware of this. Less than half of respondents indicated that personal information on patients' routines, background and preferences was routinely collected, with an additional $15 \%$ indicating that they did not know whether such information was collected.

Forty percent of respondents indicated that they did not know whether there was a designated "dignity lead" available to them to consult for advice and support. A further third indicated that such a designated role did not exist for their unit. Similarly, $72 \%$ indicated that they did not have access to peer support or reflective practice groups. With regard to gaining access to and support from other members of the healthcare team, $76 \%$ and $66 \%$ respectively either agreed or strongly agreed that they had access to and support from occupational and physiotherapy and geriatric medicine services, with 55\% confirming access to or support from social work. Just $40 \%$ agreed or strongly agreed that they had access to and support from liaison psychiatric services.

With regard to mealtimes, over three quarters of respondents indicated that a system was in place to ensure all staff was aware of patients who have difficulties at mealtimes. A similar number indicated that a system existed for the reporting of non-consumption of meals. The majority of respondents (90\%) agreed that there was a system to ensure that patients were given food that they had chosen, and that met their specific dietary needs (for example, vegetarian or diabetic diets). 
However one third of respondents either indicated that their unit did not provide meals or snacks to patients at any time, or that they did not know.

\subsection{I nformation sharing and family carer involvement}

Nurses were asked a series of questions with responses of yes / no or don't know regarding systems in place for communication and information sharing between staff and family carers. Sixty three per cent of respondents indicated that there was a system in place in their unit to ensure that staff were aware of the extent of family carers' involvement in care. The majority of (86\%) reported that this system included details on how family carers could be contacted. However only $46 \%$ agreed that the system involved making patients or carers aware of the complaints procedure and just $56 \%$ agreed that the system clearly outlined the information to be shared with family carers. Just over half of the respondents indicated that patients on their units were allocated a named nurse (or other health care staff member) that carers could contact for information.

\section{Discussion}

The future prevalence of dementia in Ireland is expected to increase, as in other countries. Currently, 29\% of older people admitted to Irish acute hospitals have dementia ${ }^{[3]}$ and this will increase as dementia prevalence increases. However, the results of this study show that knowledge for dementia care in acute hospitals is insufficient, and nurses considered their education in dementia care to be inadequate. Less than half of our sample were aware of the different types of dementia, and reported little guidance on the management of responsive behaviours. These results are similar to recent studies in the $\mathrm{UK}^{[22]}$.

This study was limited in sample size and geographical spread. However the results demonstrate that, despite a national dementia education programme, there remains a knowledge deficit among nurses in acute care settings. This may be due in part to the lack of a dementia strategy in Ireland (due to be published in the second half of 2014), meaning that dementia education is not yet a priority for senior acute hospital staff. The providers of the national dementia education programme have noted a poor uptake of offered training in acute hospitals. This survey did not explore whether this poor uptake reflected poor prioritisation of dementia training at management level, or whether it was a result of difficulties in replacing clinical staff to allow training. However, this survey clearly indicates that nurses at ward level are aware of their poor dementia knowledge and are open to dementia training.

Similar to Gandesha et al, ${ }^{[22]}$ the authors recommend strengthened awareness and management support for enhanced and specialist skills in dementia care for nurses practicing in acute care settings. Recent health service strategy for older adult care in Ireland has emphasised a service that is responsive to the changing needs and preferences of older people and is focused on person centred safe care ${ }^{[27]}$.

One of the main issues reported by nurses was that of inadequate resources, particularly with ward staffing levels. This issue was also raised in a recent "Irish National Audit of Dementia Care" ${ }^{[12]}$. Although there was a system of reporting inadequate staffing levels, reports were not dealt with in a timely manner. Such a lack of resources can lead to poor outcomes for dementia patients, as previously reported by Chaabane ${ }^{[6]}$. In past research, nutritional needs of patients with dementia were found not to be assessed ${ }^{[2,12,14]}$. In contrast, nurses in our study reported that patients with dementia were given the food they had chosen and a system was in place to ensure that all staff was aware of patients experiencing difficulties at mealtimes. However they also reported a lack of flexibility in meal times and snacks. Time to get to know the patient or ensure their comfort was also reported to be lacking in this study. This is an important issue, as it is important to develop effective communication methods that meet the individual needs of people with dementia ${ }^{[28]}$. Nurses and other health professionals need to devote time to develop a person centred approach to care and strategies to promote enablement and empowerment of individuals. 
This also requires support for their role within the acute care environment from management and peers. However nurses in our study reported low to no support from peers or other members of the health care team. Although overall, nurses in our study indicated that they felt supported in their role by colleagues and management, and they had access to services such as occupational therapy, physiotherapy and psychiatric liaison, nurses indicated a perceived lack of leadership and advice within their units with regard to dementia care. A key recommendation from the Irish National Audit of Dementia Care in Acute Hospitals ${ }^{[12]}$ was that each hospital would have "responsibility for developing a training and knowledge strategy to ensure that all staff are provided with basic training in dementia awareness, and a locally agreed specified proportion receive higher level training (including dementia champions)". Similarly, the recently published "Irish National Dementia Educational Needs Analysis 2014" [29] prioritises practice development and dementia champions programmes for all nurses and Allied Health Professionals.

\section{Conclusion}

The insufficiency of knowledge in dementia care reported by frontline nursing staff in acute care settings is of concern. Adequate educational resources for dementia specific training and education are available in Ireland, and this study indicates that acute hospital nurses are aware of their insufficient knowledge and are open to training. It is therefore time for senior nurses and health service management to prioritise dementia training for acute hospital staff and hence prepare nurses for dementia care in acute care environments.

\section{References}

[1] Cahill S, O’Shea E, Pierce M. A Research Review for Ireland's National Dementia Strategy. DSIDC’s living with Dementia Research Programme, School of Social Work and Social Policy, Trinity College, Dublin and Irish Centre for Social Gerontology, National University of Ireland, Galway; 2012: 11p.

[2] Alzheimer's Society Counting the Cost: Caring for People with Dementia on Hospital Wards, Alzheimer's Society, London; 2009.

[3] Trawley S, Barrett A, Browne V, Manning E, Cahill S, Linehan J, O'Sullivan K, Woods N, Meagher D, O'Regan N, Clune Y, Molloy DW, Timmons S. Dementia is prevalent in older people admitted to acute hospitals, but often undiagnosed: A prospective multicentre study. Irish Journal of Medical Science. 2013; 182 (Suppl 6): 151.

[4] Economic and Social Research Institute Activity in Acute Public Hospitals in Ireland: Annual Report 2009, ESRI, Dublin.

[5] Sampson EL, Blanchard MR, Jones L, Tookman A. and King M. Dementia in the acute hospital: prospective cohort study of prevalence and mortality, British Journal of Psychiatry. 2009; 195(1): 61-6. PMid:19567898 http://dx.doi.org/10.1192/bjp.bp.108.055335

[6] Chaabane F. Falls Prevention in Older Patients with Dementia Nursing Standard. 2007; 22(6): 50-60.

[7] Beer C, Flicker L, Almeido OP. Factors Associated with Self and Informant Ratings of the Quality of Life of People with Dementia Living in Care Facilities: A Cross Sectional Study. PLoS ONE. 2012; 5(12): e15621. PMid:21179448 http://dx.doi.org/10.1371/journal.pone.0015621

[8] Edelman P, Fulton BR, et al. A Comparison of Three Methods of Measuring Dementia-Specific Quality of Life: Perspectives of Residents, Staff, and Observers. The Gerontologist. 2005; 45(suppl 1): 27-36. PMid:16230747 http://dx.doi.org/10.1093/geront/45.suppl_1.27

[9] Smith J. Communication and Dementia. Nursing Older People. 2001; 12(10): 14-5. PMid:12008361 http://dx.doi.org/10.7748/nop2001.02.12.10.14.c2150

[10] Moyle W, Murfield JE, et al. Assessing quality of life of older people with dementia: a comparison of quantitative self-report and proxy accounts. Journal of Advanced Nursing. 2012; 68(10): 2237-2246. PMid:22211637 http://dx.doi.org/10.1111/j.1365-2648.2011.05912.x

[11] Royal College of Psychiatrists’ Centre for Quality. National Audit of Dementia (Care in General Hospitals): Preliminary Findings of the Core Audit, Royal College of Psychiatrists. London; 2010.

[12] de Siún A, O’Shea E, Timmons S, McArdle D, Gibbons P, O’Neill D, Kennelly SP, Gallagher P. Irish National Audit of Dementia Care in Acute Hospitals. Cork: National Audit of Dementia Care; 2014.

[13] Cahill S, Doran D, Watson M. Guidelines for nursing homes delivering end-of-life care to residents with dementia across the island of Ireland. Quality in Ageing and Older Adults. 2012; (13)1: 60-71. 
[14] Royal College of Psychiatrists' Centre for Quality National Audit of Dementia (Care in General Hospitals): Second Round Audit Report and Update Royal College of Psychiatrists, London. 2012 [cited 2014 April 10]. Available from: https://www.rcpsych.ac.uk/pdf/NAD\%20NATIONAL\%20REPORT\%202013.pdf.

[15] Chater K, Hughes N. Strategies to deliver dementia training and education in the acute hospital setting. Journal of Research in Nursing. 2013; 18: 578 published online 11 June 2012.

[16] Kada S, Nygaard HA, et al. Staff attitudes towards institutionalised dementia residents. Journal of Clinical Nursing. 2009; 18(16): 2383-2392. PMid:19583668 http://dx.doi.org/10.1111/j.1365-2702.2009.02791.x

[17] Grant LA, Kane RA, Potthoff S J, Ryden M. Staff training and turnover in Alzheimer special care units: comparisons with non-special care units Geriatric Nurse. 1996; 17(6): 278-82.

[18] Nolan L. Caring for people with dementia in the acute setting: a study of nurses' views. Br J Nurs. 2007; 16(7): 419-422. PMid:17505366 http://dx.doi.org/10.12968/bjon.2007.16.7.23245

[19] Baillie L. Caring for older people with dementia in hospital. Part one: challenges. Nursing Older People. 2012; 24(8): 33-37. PMid:23189504 http://dx.doi.org/10.7748/nop2012.10.24.8.33.c9312

[20] Baillie L, Merritt J, et al. Caring for older people with dementia in hospital. Part two: strategies. Nursing Older People. 2012; 24(9): 22-26. PMid:23311277 http://dx.doi.org/10.7748/nop2012.11.24.9.22.c9366

[21] Traynor V, Inoue K, et al. Literature review: understanding nursing competence in dementia care. J Clin Nurs. 2011; 20(13-14): 1948-1960. PMid:21401762 http://dx.doi.org/10.1111/j.1365-2702.2010.03511.x

[22] Gandesha A, Souza R, et al. Adequacy of training in dementia care for acute hospital staff. Nursing Older People. 2012; 24(4): 26-31. PMid:22708154 http://dx.doi.org/10.7748/nop2012.05.24.4.26.c9070

[23] McGlade C, O’Connell S, Linehan J, Timmons S. Challenging behaviour in an acute hospital - incidence, implications, staff perceptions and patient experience. Irish Journal of Medical Science. 2009; 178(S8): S335.

[24] de Siún A, Manning M. National Dementia Project: Dementia Education Needs Analysis Report. Health Service Executive, Dublin; 2010.

[25] Department of Health Social Services \& Public Safety Improving Dementia Services in Northern Ireland- A Regional Strategy, Department of Health Social Services and Public Safety, Belfast; 2011.

[26] Manning M, Quinn A, Lynch D, Hayden C, Craig C. Connolly, M. "National Dementia Education Project: An Evaluation of Progress to Date” Irish Journal of Medical Science. 2013; 182 (Suppl 6): S179-S296.

[27] Department of Health National Positive Ageing Strategy[Internet]. 2013[cited 2014 June 8]. Available from: http://www.galwayhealthycities.ie/uploadedfiles/National\%20Positive\%20Ageing\%20Strategy\%202013.pdf

[28] Veselinova C Influencing Communication and Interaction in Dementia. Nursing \& Residential Care. 2014; 16(3): pp 162-166. http://dx.doi.org/10.12968/nrec.2014.16.3.162

[29] Irving K, Piasek P, Kilcullen S, Coen A, Manning M. Irish national dementia educational needs analysis. Dublin: DCU; 2014. 